\title{
Quality Management in the Czech Republic and Poland - Comparative Analysis
}

\author{
Piotr ROGALA ${ }^{1}$, Marian KACHNIARZ ${ }^{2}$ \\ ${ }^{1}$ Wrocław University of Economic, Jelenia Góra, Poland \\ piotr.rogala@ue.wroc.pl \\ ${ }^{2}$ Wroclaw University of Environmental and Life Sciences, Wrocław, Poland \\ marian.kachniarz@upwr.edu.pl
}

\begin{abstract}
The article compares two bordering countries i.e. the Czech Republic and Poland, in chosen aspects concerning broadly defined quality management. The analysis bases on the outcome of "World State of Quality" project, which, for the article was supplemented with additional calculations and information. The research proves that the Czech Republic is characterized by much higher development in the area of quality management. The Czech Republic recorded better results in 16 out of 21 indicators included in the research. In the ranking of European Union countries, which was prepared on the basis of combined value of those 21 indicators, the Czech Republic was $11^{\text {th }}$ on the list while Poland was $20^{\text {th }}$. There was an additional analysis based on 4 indicators which are most significant for quality management : (1) number of ISO 9001 certified organizations, (2) number of organizations recognized by quality awards, (3) number of International Academy for Quality members (4) number of certified quality professionals. It appeared that Poland had not achieved better results than the Czech Republic in any of them.
\end{abstract}

Keywords: Quality Management, Comparative Analysis, the Czech Republic, Poland.

\section{Introduction}

Quality management can be defined as an approach to improving the effectiveness and flexibility of business as a whole, meeting customer's requirements both external and internal to the organization. It is essentially a way of organizing and involving the whole organization, every department, every single person at every level [8]. This approach, and in particular Total Quality Management (TQM), has been one of the most dominating and pervasive managerial approaches all over the world during the last three decades. In particular, from the late 1980s to the middle of the 1990s, the term TQM became more and more frequently used in the management literature as well as in the business world. However, during the first years of the new millennium, the term TQM seems to have lost its attractiveness in the industrialized parts of the world, and instead new terms like Business Excellence, Organizational Excellence, 
Six-Sigma, and Lean seem to have overtaken the position of TQM even though the contents of these new terms are within the framework of quality management [5].

Currently, the quality management initiative is most widely used in the implementation of ISO standards (first of all ISO 9001) which are practically indispensible to compete in international markets. The standards represent a significant initial step for manufacturing organizations on the way to quality management since they involve a lower initial degree of commitment to their principles. However, another, less optimistic, vision argues that firms that implement ISO standards only aim at obtaining a certification which they can use to develop their business without really committing themselves to quality management [3].

Despite a vast scientific literature on quality management, few researches have been carried out to compare countries in the area and they can be divided into two groups.

The first includes researches on broadly defined quality which usually concern the quality of life and sustainable development such as for example: European quality of life examination [4] and the rankings of sustainable development [1]. The projects deal with the satisfaction with the quality of life of certain countries' inhabitants.

The second group of researches is of a quite different nature. They are limited to only one branch or a method of quality management etc. For example Sampaio with its partners evaluated chosen countries basing on the number of ISO 9001 certificates [7]. However such projects focus only on specific fraction of quality management so they do not provide a wider perspective.

The goal of the article is to compare two bordering countries i.e. the Czech Republic and Poland. The matters of a multidimensional analysis are chosen issues/indicators connected with quality management. The article exploits the outcome of "World State of Quality" project which is supplemented with additional calculations on observations prepared by the author of the article.

\section{2 "World State of Quality" Project}

\subsection{Methodology}

The research Project "World State of Quality" was conducted by a team of five representatives of University of Coimbra, University of Minho and National Observatory of Human Resources from Portugal [10].

Their work resulted with designing a 10 dimensional model in which the first half defines the potential while the latter describes the achievements. Every dimension consists of 2 (in one case 3) detailed indicators so the evaluation uses 21 such indicators in total. The dimensions and indicators used in the evaluation of the countries are presented in table 1. 
Table 1. Dimensions and indicators used in"World State of Quality” project.

\begin{tabular}{|c|c|c|c|}
\hline No & Dimension & & Indicator \\
\hline \multirow{3}{*}{1} & \multicolumn{3}{|r|}{-Enablers- } \\
\hline & \multirow[t]{2}{*}{ Organizations } & 1 & Number of ISO 9001 Certified Organizations (i1) \\
\hline & & 2 & $\begin{array}{l}\text { Number of Organizations Recognized by Quality } \\
\text { Awards (i2) }\end{array}$ \\
\hline \multirow[t]{2}{*}{2} & Professionals & 3 & $\begin{array}{l}\text { Number of International Academy for Quality Members } \\
\text { (i3) }\end{array}$ \\
\hline & & 4 & Number of Certified Quality Professionals (i4) \\
\hline \multirow[t]{2}{*}{3} & Research & 5 & Number of Indexed Quality Paper Published (i5) \\
\hline & & 6 & $\begin{array}{l}\text { Number of Universities in International Research } \\
\text { Rankings (i6) }\end{array}$ \\
\hline \multirow[t]{2}{*}{4} & Education & 7 & OECD PISA Test Results (i7) \\
\hline & & 8 & Lifelong Learning (i8) \\
\hline \multirow[t]{3}{*}{5} & Health & 9 & Healthy Life Expectancy (i9) \\
\hline & & 10 & At Birth Mortality Rates (i10) \\
\hline & & & -Results- \\
\hline \multirow[t]{2}{*}{6} & Competitiveness & 11 & Global Competitiveness Index (i11) \\
\hline & & 12 & Gross Domestic Product (i12) \\
\hline \multirow[t]{2}{*}{7} & Social cohesion & 13 & Gini Index (i13) \\
\hline & & 14 & People in Risk of Poverty and Social Exclusion (i14) \\
\hline \multirow[t]{2}{*}{8} & Sustainability & 15 & Environmental Wellbeing Results (i15) \\
\hline & & 16 & Ecological Footprint (i16) \\
\hline \multirow[t]{2}{*}{9} & Innovation and & 17 & Global Innovation Index (i17) \\
\hline & entrepreneurship & 18 & Ease of Doing Business Results (i18) \\
\hline \multirow[t]{3}{*}{10} & Satisfaction & 19 & Quality of Life (i19) \\
\hline & & 20 & Job Satisfaction (i20) \\
\hline & & 21 & Unemployment Rate (i21) \\
\hline
\end{tabular}

\subsection{Main Results}

The indicators presented in the above table were used in the process of building the European countries ranking. The process of designing the ranking had three stages.

The first step was establishing indicators values for every of the 28 countries which provided 21 rankings as there were 21 indicators included. In every ranking the countries were given ranks reflecting their position in individual charts.

The second stage defined the weight of separate indicators which involved 19 additional experts in quality management. The group consisted among others of representatives of American Society for Quality, members of International Academy for Quality and representatives of European Organization for Quality. Their opinions were used to establish the weight of individual indicators and "Quality of life" was chosen as the most significant indicator. The weight of this indicator was 0.058 while the lowest weight (0.036) was given to the number of International Academy for Quality Members 
The final stage included calculating the value of the aggregate indices of quality (Overall European Quality Scoreboard - OEQS) for every country in the project. The lower values of this indicator mean better evaluation of the situation in certain countries. Therefore, it can be claimed that OEQS is an indicator which bases on quality management and describes the level of a certain country's development. The ranking of countries created with this indicator is presented in table 2.

Table 2. Ranking of European Union countries.

\begin{tabular}{llc}
\hline No & \multicolumn{1}{c}{ Country } & $\begin{array}{c}\text { Overall European } \\
\text { Quality Scoreboard }\end{array}$ \\
\hline 1 & Finland & 7.85 \\
2 & Austria & 7.97 \\
3 & Sweden & 8.33 \\
4 & Netherlands & 8.45 \\
5 & Denmark & 9.05 \\
6 & United Kingdom & 10.20 \\
7 & Luxembourg & 10.86 \\
8 & Germany & 10.90 \\
9 & Ireland & 11.18 \\
10 & Ireland & 11.45 \\
11 & Slovenia & 12.76 \\
12 & Czech Republic & 12.99 \\
13 & Belgium & 13.10 \\
14 & Spain & 14.24 \\
15 & Portugal & 14.40 \\
16 & Estonia & 14.52 \\
17 & Malta & 14.65 \\
18 & Italy & 15.65 \\
19 & Slovakia & 17.00 \\
20 & Poland & 17.67 \\
21 & Hungary & 17.72 \\
22 & Cyprus & 17.83 \\
23 & Romania & 18.03 \\
24 & Lithuania & 18.61 \\
25 & Latvia & 19.39 \\
26 & Croatia & 19.65 \\
27 & Greece & 19.96 \\
\hline & Bulgaria & 21.97 \\
\hline & & \\
28 &
\end{tabular}


Best evaluations of development were given for the following countries: Finland, Austria, Sweden, the Netherlands and Denmark while Bulgaria, Greece, Croatia, Latvia and Lithuania were claimed to be at the lowest developmental level.

\section{Comparative analysis}

\subsection{Overall European Quality Scoreboard}

The value of the Overall European Quality Scoreboard for the Czech Republic was 12.76 providing the country the $11^{\text {th }}$ position among 28 European Union countries in the ranking. Poland was worse at the $20^{\text {th }}$ place with the Overall European Quality Scoreboard at 17.67 level. This observation supports the results of numerous researches available in scientific literature which indicate a higher level of development of the Czech Republic in comparison to Poland. For example A. Bluszcz compared European countries in the area of the sustainable development level. She prepared a ranking in which the Czech Republic was at the $14^{\text {th }}$ place and Poland was $20^{\text {th }}$ [2]. Also in one of the best known rankings of countries created on the basis of the value of Human Development Index, the Czech Republic is at the $28^{\text {th }}$ while Poland at the $36^{\text {th }}$ place (it is a ranking of a global nature which covers 188 countries)[6].

Analyzing the values of the detailed indicators for both countries (see Fig. 1) it is noticeable that only in 5 out of 21 indicators Poland was evaluated as better than the Czech Republic. The indicators are:

OECD PISA Test Results (i7). The indicator is the score obtained for mathematics in PISA (Programme for International Student Assessment) results, derived from a test aimed at evaluating the knowledge and skills of 15-year-old students. It is worth pointing out that it is the only indicator of potential (among 10) in which Poland had better results than the Czech Republic. In this case Poland was $4^{\text {th }}$ and the Czech Republic was $11^{\text {th }}$.

- Environmental Wellbeing Results (i15). The indicator provides an aggregated evaluation of overall environmental performance (for example: undernourished people in total population and area for organic farming in total agricultural area) achieved at any given country [9]. In this ranking Poland was $16^{\text {th }}$ and the Czech Republic $24^{\text {th }}$.

- Ecological Footprint (i16). The indicator is defined as the demand of nature regarding the amount of resources used by a given country. In this ranking Poland was $11^{\text {th }}$ and the Czech Republic $15^{\text {th }}$.

Ease of Doing Business Results (i18). The indicator scores the regulatory environment and bureaucracy in a given country according to several matrices that allow to measure efficiency in company creation and development. In this case Poland was $12^{\text {th }}$ and the Czech Republic was $18^{\text {th }}$. 
- Quality of Life (i19). The indicator is directly related to perceived life satisfaction, expressed by citizens from any given country. In this ranking Poland was $9^{\text {th }}$ and the Czech Republic $17^{\text {th }}$.

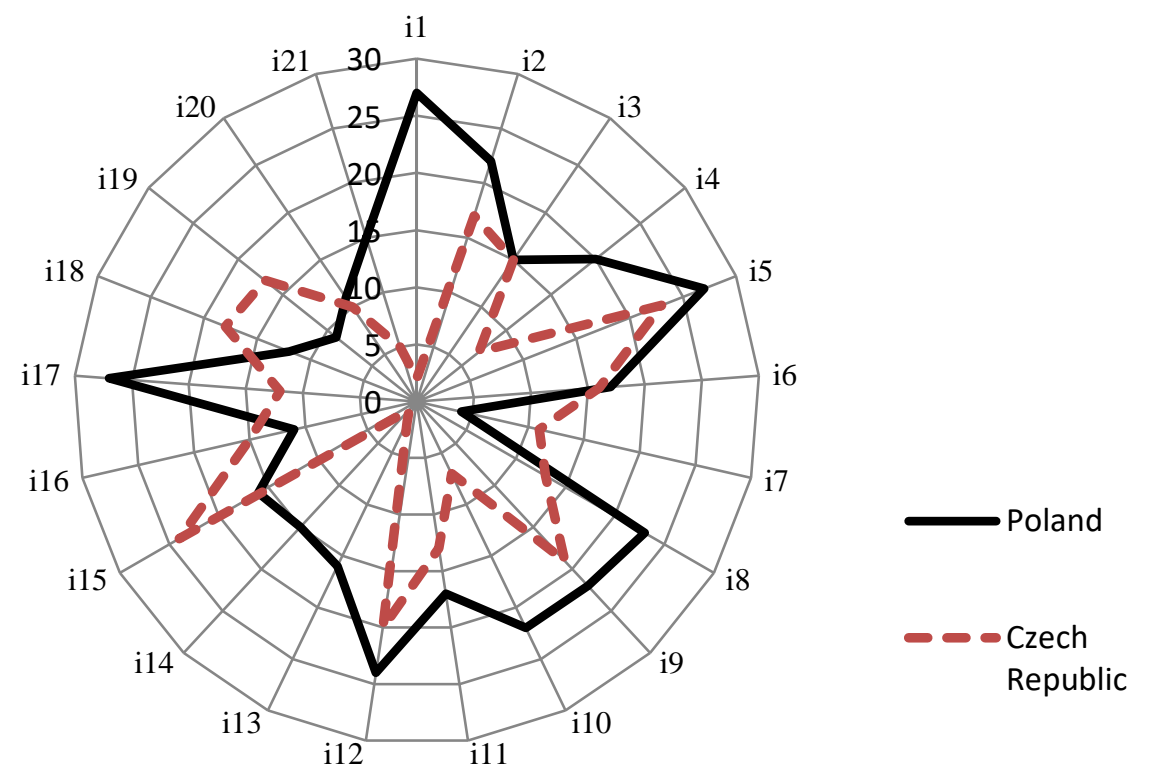

Fig. 1. Comparison of the places of Poland and the Czech Republic in the rankings.

The biggest diversity was noticed in the rankings prepared on the basis of the following indicators:

- Number of ISO 9001 Certified Organizations (i1). The indicator measure the number of ISO 9001 certificates that are issued by certification bodies in any given country. That number is divided by each country's total population. In this ranking Poland was $27^{\mathrm{h}}$ and the Czech Republic $2^{\text {nd }}$.

- Gini Index (i13). The indicator measures the degrees of inequality and dispersion of income across families and individuals at any given country. In this ranking Poland was $18^{\text {th }}$ and the Czech Republic $12^{\text {th }}$.

- People in Risk of Poverty and Social Exclusion (i14). The indicator describes the percentage of people that are in risk of poverty and social exclusion according to a multidimensional approach that takes into account several dimensions (monetary poverty, material deprivation and low work intensity), for any given country. In this ranking Poland was $15^{\mathrm{h}}$ and the Czech Republic $1^{\text {nd }}$ 


\subsection{Quality management}

Among 21 indicators used in the"World State of Quality" project only 4 refer directly to quality management:

- Number of ISO 9001 Certified Organizations (i1), the description of this indicator is included in the previous chapter.

- Number of Organizations Recognized by Quality Awards (i2). The indicator measures the total number of organizations, in each country, that have an updated recognition according to the EFQM Model Excellence. The number is divided by each country's total population.

- Number of International Academy for Quality Members (i3). The indicator measures the total number of International Academy for Quality members in any given country. The number is divided by each country's total population.

- Number of Certified Quality Professionals (i4). The indicator measures the total number of certified quality professionals, in any given country according to the following organizations: International Register of Certified Auditors, American Society for Quality, European Organization for Quality and European Foundation for Quality Management. The number is divided by each country's total population.

If the analysis includes only these 4 indicators (applying the same method of calculating the aggregate indices which was used to calculate the OEQS) the Czech Republic will achieve 0.43425 while Poland 0.96875. It sets the Czech Republic at the $6^{\text {th }}$ place among 28 European Union countries. In the same chart Poland is at the $27^{\text {th }}$ place.

For 3 detailed rankings i.e. based on i1, i2 and i4 indicators, the Czech Republic was at a better than Poland place. In the ranking basing i3 indicator both the Czech Republic and Poland were at the $15^{\text {th }}$ place. It is the result of the situation that only 14 countries in the ranking have their members in the International Academy for Quality. All remaining countries were given the $15^{\text {th }}$ place. 


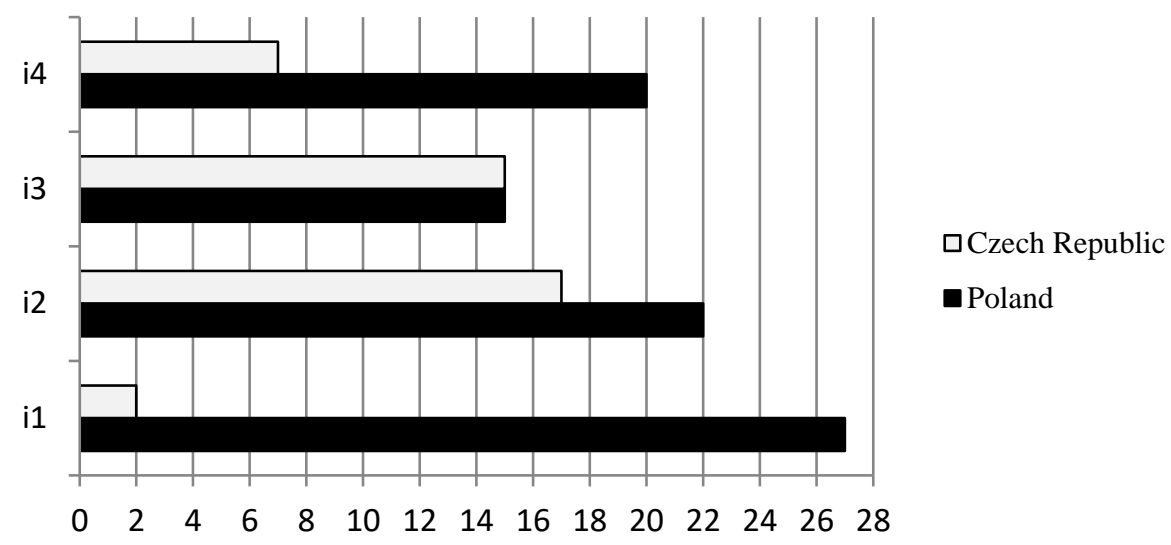

Fig. 2. The position of the Czech Republic and Poland in the rankings concerning quality management.

The countries at top positions in the ranking based on the aggregate indices concerning quality management are: Slovenia, Austria, Spain, Ireland and Germany. At the lowest positions beside Poland were: Lithuania, Latvia, Croatia and Denmark.

\section{Conclusions}

The paper compares the Czech Republic and Poland in the area of chosen aspects concerning both narrow and broad sense of quality management. In both cases the Czech Republic is ahead of Poland in the level of development. The research ought to be continued in order to establish the sources of the current situation.

The study has some limitations that need to be kept in mind. They concern first of all the methodology adopted for the needs of the "World State of Quality" project and later used for the preparation of this article. Including some of the indicators such as e.g. the number of International Academy for Quality members in the analysis can be also doubtful. At the same time there are many more significant indicators (related for example to Lean Management and TQM) which should have been included but were omitted due to the lack of available data. The method of calculating the aggregate indices can also be arguable as it was based on the positions in the rankings instead of using the values of detailed indicators.

\section{References}

1. Antanasijević, D., Pocajt, V., Ristić, M., Aleksandra Perić-Grujić, A.: A differential multicriteria analysis for the assessment of sustainability performance of European countries: Beyond country ranking", Journal of Cleaner Production 1(165), 213-220 (2017), DOI 10.1016/j.jclepro.2017.07.131 
2. Bluszcz, A.: Classification of the European Union member states according to the relative level of sustainable development. Quality \& Quantity 6(50), 2591-2605 (2016), DOI: 10.1007/s11135-015-0278-x.

3. Dahlgaard-Park, S-M, Chen Ch-K, Jiun-Yi Jang J-Y, Jens J. Dahlgaard J.: Diagnosing and prognosticating the quality movement - a review on the 25 years quality literature, Total Quality Management 1(24), 1-18 (2013), DOI: 10.1080/14783363.2012.756749.

4. European Foundation for the Improvement of Living and Working Condition, www.eurofound.europa.eu, last accessed 2017/09/14

5. Gutiérrez Gutiérrez, L., J., Ignacio Tamayo Torres, I., J., Vanesa Barrales Molina V., B.: Quality management initiatives in Europe: An empirical analysis according to their structural elements, Total Quality Management 6(21), 577-60 (2010), DOI: 10.1080/14783363.2010.483064.

6. Human Development Reports, http://hdr.undp.org/en/2016-report, last accessed 2017/09/12.

7. Sampaio, P., Saraiva, P., Gomes, A: ISO 9001 European Scoreboard: an instrument to measure macroquality, Total Quality Management \& Business Excellence, 3-4 (25), 309 318 (2014), DOI 10.1080/14783363.2013.807683

8. Soltani E, Lai, P-Ch, Javadeenm S, Gholipour, T. H.: A review of the theory and practice of managing TQM: An integrative framework, Total Quality Management 5(19), 461-479 (2008), DOI: 10.1080/14783360802018103.

9. Sustainable Society Index, http://www.ssfindex.com/ssi/indicator-description, last accessed 2017/09/14

10. World State of Quality, http://wsq.dps.uminho.pt/index.html, last accessed 2017/09/12. 